\title{
Assessment of Buildings with Ventilated Facade Systems and Evaluation of Point Thermal Bridges
}

JSACE 2/11

Assessment of Buildings with Ventilated Facade Systems and Evaluation of Point Thermal Bridges

Received 2015/01/25

Accepted after revision 2015/06/01
Jolanta Šadauskienè*, Lina Šeduikytè

Faculty of Civil Engineering and Architecture, Kaunas Technology University Studentu Str. 48, LT- 51367, Kaunas, Lithuania

\section{Juozas Ramanauskas}

Faculty of Civil Engineering and Architecture, Kaunas Technology University Studentu Str. 48, LT- 51367, Kaunas, Lithuania

Institute of Architecture and Construction of Kaunas University of Technology Tunelio Str. 60, LT-44405, Kaunas, Lithuania

\section{Andrius Buska}

ROCKWOOL UAB, A.Gostauto Str. 40B, LT-01112 Vilnius, Lithuania
*Corresponding author: jolanta.sadauskiene@ktu.lt

\section{Гrossef http://dx.doi.org/10.5755/j01.sace.11.2.12606}

Analyzes of influence of the point thermal bridges of buildings with ventilated facade systems on the thermal properties of envelops are presented in the paper. The relation between the separate components of the envelop were made: thermal properties and thickness of supporting wall's layer; value of thermal conductivity and thickness of insulation layer. Studies have shown, that the value of the point thermal transmittance, which depended on the thermal properties of the envelop and thickness of the layers, might increase to 35\%. The higher thermal conductivity coefficient of the material of the supporting wall and thickness of the insulation layer, the larger value the point thermal transmittance. And contrary, if the thickness of the supporting wall and coefficient of thermal conductivity of insulation layer was increased, the value the point thermal transmittance was decreased. It is possible to determine the value of thermal bridges of certain construction design solution by simplified calculations, according to the existing dependencies formulas or graphics. In this case it's necessary to have dependence of the point thermal bridges from thermal insulation properties and dimensions of envelop layers.

KEYWORDS: thermal bridges, thermal conductivity, supporting wall, thermal insulation.

\section{ktu \\ (1923}

Journal of Sustainable Architecture and Civil Engineering Vol. 2 / No. 11 / 2015 pp. 59-71

DOl 10.5755/j01.sace.11.2.12606 (c) Kaunas University of Technology 
In order to implement European Energy Performance of Buildings Directive (EPBD) requirements, for the reduction of energy consumption, several national requirements in European countries are created for thermal properties of building envelops, as well as calculation methodologies for evaluation of energy efficiency performance of buildings. Each European country presents they own methodology for building energy efficiency performance (DIN V 18599 in Germany, DOCET in Italy, CALENER in Spain, NS 3034 in Norway, etc.), which is based on identification of factors which are increasing building energy losses. One of such factors are building thermal bridges, which are appearing because of full or partial penetration of the building envelope by materials with a different thermal conductivity, and/or a change in thickness of the fabric, and/or a difference between internal and external areas, such as occur at wall/floor/ceiling junctions. Literature review shows, that the total impact of thermal bridges on the heating energy need is in general considerable and can vary from $5 \%$ to $39 \%$ (Theodosiou and Papadopoulos 2008; Citteio and et al. 2008, Evola and et al. 2011.). This depends on several factors such as weather conditions, level of insulation, the thermal bridges constructive solution, type of building (use and geometry) and of the method used to implement its effect within the calculation of the building energy demand (Martin and et al. 2011, Ascione and et al. 2014, Ge and et al. 2013, Cappelleti and et al. 2011, Theodosiou and et al. 2014).

Thermal bridges can affect a single point, a linear area or a spatial configuration. Usually, in the calculation of the building energy demand liner thermal bridges are evaluated, which occurs at the junction between two or more elements of the building envelope. It's easy, as in most cases values of liner thermal transmittance ( $\psi$-value) of standard parts are presented in thermal bridge atlases (Capozzoli and et al. 2013). The most common atlas is represented by the European Standard EN ISO 14683, witch contains seventy-six cases referring to eight typologies of thermal bridges (roofs, corners, intermediate floors, internal walls, slab-on-ground floors, suspended ground floors, pillars, window and door openings).

However, when assessment of point thermal bridges is made, they influence on the total energy balance of the building is more complicated. That's why the effect of the point thermal bridges is often neglected in the analyses aimed at defining the building energy efficiency performance. However, it's an important factor when projects on low energy buildings are made. Studies are showing, that if continuous metal profiles are used for fixing thermal insulation layer, and profiles are crossing the insulation layer, the thermal resistance could decrease twice (Gomes and et al. 2013, Qasass and et al. 2014). If these additional heat losses through the thermal bridges are not evaluated or evaluated incorrectly, the owner of the building could feel deceived because of incorrect building energy efficiency performance declaration. Furthermore, problems because of selection of proper power for the heating system might appear. In this case, under extreme temperature differences between the outside and inside temperatures, required indoor thermal conditions might not be ensured. Because of low surface temperatures, this will result in moisture condensation and mold growth at the places of thermal bridges (Angelis and Serra 2014).

The aim of this work was to determine the point thermal transmittance ( $x$-value) of the fixing elements, which were made from aluminum. As well as setting of dependence from the thickness of insulation layer, from coefficient of thermal conductivity of insulation material and from the type and thickness of the supporting wall (brick masonry, monolith, frame structure and ctr.).

\section{Methodology}

\section{Calculation of thermal transmittance value through building elements and thermal bridges}

The calculation of the transmission heat transfer coefficient includes the contribution due to thermal bridges, according to Eq. 1: 


$$
H_{D}=\Sigma_{\mathrm{i}} A_{i} \cdot U_{i}+\Sigma_{k} l_{k} \cdot \Psi_{k}+\Sigma_{j} \chi_{j}
$$

where: $A_{i}$ - is the area of element $i$ of the building envelope, in $\mathrm{m}^{2} ; U_{i}$ - is the thermal transmittance of element $i$ of the building envelope, in $\mathrm{W} /\left(\mathrm{m}^{2} \cdot \mathrm{K}\right) ; l_{k}$ - is the length of linear thermal bridge $k$, in $m ; \Psi_{k}$ is the linear thermal transmittance of linear thermal bridge $k$, in $\mathrm{W} /(\mathrm{m} \cdot \mathrm{K}) ; \mathrm{x}_{j}$ - is the point thermal transmittance of the point thermal bridge $j$, in W/K. Calculations of U-values follow (STR 2.05.01:2013)

Thermal bridges may be defined according to EN ISO 10211. The linear thermal transmittance of the thermal bridges $(\Psi)$ is calculated as in Eq. 2:

$$
\Psi=L^{2 D}-\Sigma U_{j} \cdot l_{j}
$$

where: $L^{2 D}$ - is the linear thermal coupling coefficient obtained from a twodimensional calculation of the component separating the two environments being considered; $U_{j}$ - is the thermal transmittance of the one-dimensional component $j$ separating the two environments being considered; $l_{j}$ - is the length within the two-dimensional geometrical model over which the value of $U_{j}$ applies.

Linear thermal transmittance values depend on the system of dimensions used in calculating the areas of one-dimensional heat flow (i.e. in the calculation of $\Sigma U_{j} \cdot l_{j}$ ). But the total transmission heat transfer coefficient $H_{D}$ (Eg.1) has to evaluate all thermal bridges, it means that not only linear but also point thermal bridges have to be evaluated.

In general, the influence of point thermal bridges (insofar as they result from the intersection of linear thermal bridges) can be neglected and so the correction term involving point thermal bridges can be omitted from Equation (1). If, however, there are significant point thermal bridges, then the point thermal transmittances should be calculated in accordance with ISO 10211. The point thermal transmittance (value-x) is calculated as in Eq. 3:

$$
\chi=L_{3 D}-\sum_{i=1}^{N_{i}} U_{i}-A_{i}-\sum_{j=1}^{N_{j}} \Psi_{j}
$$

where: $L_{3 D}-$ is the thermal coupling coefficient obtained from a 3-D calculation of the 3-D component separating the two environments being considered; $U_{j}$ - is the thermal transmittance of the 1-D component $i$ separating the two environments being considered; $A_{i}$ - is the area over which the value $U_{i}$ applies; $\Psi_{j}$ - are linear thermal transmittances; $l_{j}$ - is the length over which the value of $\Psi_{j}$ applies; $N_{j}$ - is the number of 2-D components; $N_{i}$ - is the number of 1-D components.

When the point thermal transmittance ( $x$-value) of fixing elements is determined by $3-\mathrm{D}$ methodology, then specific heat losses through the repeated area of the envelop with fixing element $H$ and without fixing element $H_{0}$ are calculated. The difference of these specific heat losses show the value of the point thermal transmittance (Eq. 4)

$$
\chi=H-H_{0}
$$

where: $H_{0}$ - specific heat losses through the repeated area of the envelop with fixing element, $\mathrm{W} / \mathrm{K} ; \mathrm{H}$ - specific heat losses

through the repeated area of the envelop without fixing element, $\mathrm{W} / \mathrm{K}$. 
Since fixing elements are crossing insulation layer in local arias, they influence on heat transfer is evaluated by point thermal transmittance coefficient $x, W / K$. If these point thermal bridges are repetitive in the envelop, they could be evaluated as supplement of the heat transmittance coefficient $\Delta U$ (Eq. 5), taking into account they number in $1 \mathrm{~m}^{2}$ of the envelop. If the density of the fixing elements is typical for the certain area of the envelop, it is possible to specify envelope's heat transmittance coefficient $U, W /\left(m^{2} \cdot K\right)$ at once (Eq. 6).

$$
\Delta \mathrm{U}=\chi \cdot n
$$

$$
U=U_{o}+\Delta \mathrm{U}
$$

where: $n$ - the number of the fixing elements per area, number./ $\mathrm{m}^{2}$.

where: $U_{o}$ - heat transmittance coefficient of the envelope, without evaluation of the impact of the fixing elements, $\mathrm{W} /\left(\mathrm{m}^{2} \cdot \mathrm{K}\right)$.

\section{Assessment of the point thermal bridges}

Ventilated facades with aluminum fixing elements were chosen for the calculations (Fig. 1.).

Fig. 1

The principal scheme of the ventilated facades with aluminum fixing elements: a) top view; b) side view.

1 - supporting wall; 2 - thermal insulation layer; 3 - wind insulation

layer; 4 - gasket;

5 - aluminum fixing elements; 6 - ventilated air gap; 7- facade panel

\section{Fig. 2}

Calculation scheme of the thermal bridge of fixing element
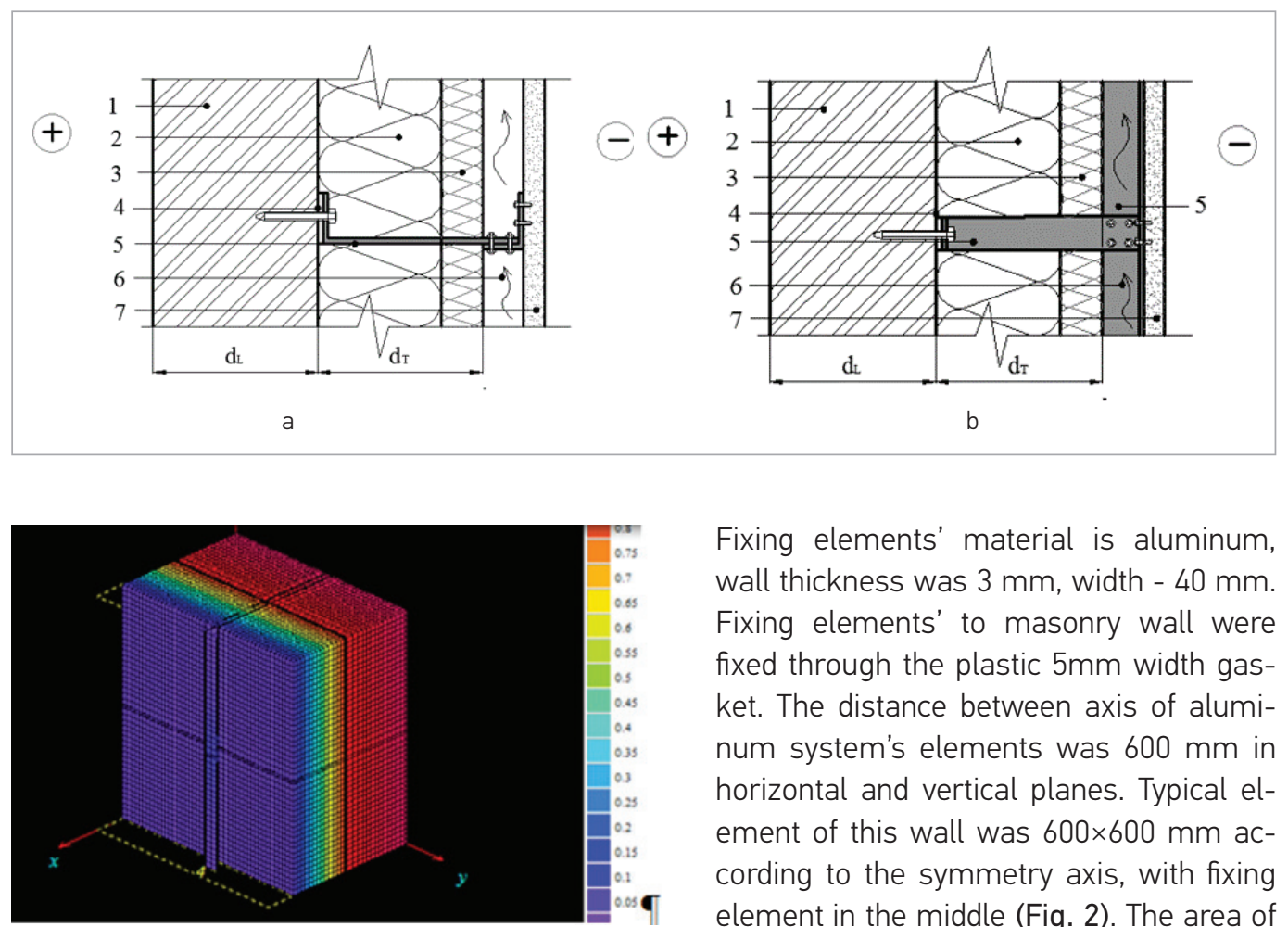

Fixing elements' material is aluminum, wall thickness was $3 \mathrm{~mm}$, width $-40 \mathrm{~mm}$. Fixing elements' to masonry wall were fixed through the plastic $5 \mathrm{~mm}$ width gasket. The distance between axis of aluminum system's elements was $600 \mathrm{~mm}$ in horizontal and vertical planes. Typical element of this wall was $600 \times 600 \mathrm{~mm}$ according to the symmetry axis, with fixing element in the middle (Fig. 2). The area of such element was $0.36 \mathrm{~m}^{2}$, and the number of fixing element in $1 \mathrm{~m}^{2}$ of the envelope's area was : $n=2.778 \mathrm{vnt} . / \mathrm{m}^{2}$.

Three dimensional temperature field calculation program HEAT 3 was used in order to determine point thermal transmittance ( $x$-value) of aluminum fixing element and dependence of this value on the construction's materials. With this program different variation of constructions were calculated. Variations are presented in Table 1.

For the analyses of point thermal bridges basic construction variant was selected: thickness of the supporting wall $d_{L}=200 \mathrm{~mm}$, thermal conductivity of the supporting wall $\lambda_{L}=0.5 \mathrm{~W} /(\mathrm{m} \cdot \mathrm{K})$, thickness of the insulation layer $d_{T}=150 \mathrm{~mm}$, Thermal conductivity of the insulation layer $\lambda_{T}=$ $0.034 \mathrm{~W} /(\mathrm{m} \cdot \mathrm{K})$. 


\begin{tabular}{c|c|c|c|c}
\hline $\begin{array}{c}\text { Var. of cal- } \\
\text { culation }\end{array}$ & $\begin{array}{c}\text { Thickness of the layer } \\
\text { of the supporting } \\
\text { wall, } \\
d_{L}, \mathrm{~mm}\end{array}$ & $\begin{array}{c}\text { Thermal conductivity } \\
\text { of the layer of the } \\
\text { supporting wall, } \\
\lambda_{L},(\mathrm{~W} / \mathrm{m} \cdot \mathrm{K})\end{array}$ & $\begin{array}{c}\text { Thickness of the } \\
\text { insulation layer, } \\
d_{T^{\prime}} \mathrm{mm}\end{array}$ & $\begin{array}{c}\text { Thermal conductivity } \\
\text { of the insulation layer } \\
\mathbf{T}_{T^{\prime}}(\mathrm{W} / \mathrm{m} \cdot \mathrm{K})\end{array}$ \\
\hline Basic data & 200 & 0.5 & 150 & 0.034 \\
\hline 1 & 200 & $0.1 \div 1$ & 150 & 0.034 \\
\hline 2 & $50 \div 500$ & 0.5 & 150 & 0.034 \\
\hline 3 & 200 & 0.5 & $100 \div 200$ & $0.030 \div 0.040$ \\
\hline 4 & 200 & 0.5 & 0.034 \\
\hline
\end{tabular}

\section{Statistical evaluation}

Regression analysis were made in order to determine empirical dependence and relation between the point thermal transmittance (value-x) and properties of construction materials, reliability and adequacy of calculation results.

The dependent variable was the point thermal transmittance (value-x), interval variables were thermal conductivity coefficients of the supporting wall and insulation layer. Correlation coefficient $R$ was used for the evaluation of the strength of connection of variables. Pearson statistics and significance level of $a=0.05$ was used for the evaluation.

The linear regression model was evaluated according to the value of the determination coefficient $R^{2}$, according to ANOVA $p$-value $<0.05$, according to VIF $\leq 4$ (no multicolinearity problems), according to all Cook's values $\leq 1$, according to compliance to correlation of signs of coefficients, according to standardized residual errors and P-P graphic.

\section{Behavior of the thermal flow through the pint thermal bridge}

Three-dimensional temperature field simulation was made in order to determine the influence of the point thermal bridge to the behavior of thermal flow in the external wall of the building, with basic data of the envelop (Fig. 3).

Thermal flow in the place of the thermal bridge is no smooth and parallel. In the warm part of insulation layer, the direction of the thermal flow is not only from the inner face, but also from the surrounding thermal insulation material. Respectively, in the cold part of the insulation layer, the direction of the thermal flow is not only to the external part, but to the thermal insulation material as well.

Depending on the material of the supporting wall, depends the capacity of the thermal flow to gather (on the cold side) or to disperse (on the worm side). The results of the movement of thermal flow are presented in Fig. 4. The results show, that if thermal conductivity of the material of the supporting wall, from the warm part of the insulation layer, is high, then there are conditions for the concentration of the high thermal flow at the place of the pint thermal bridge, close to insulation layer. Heat-conductive mate-

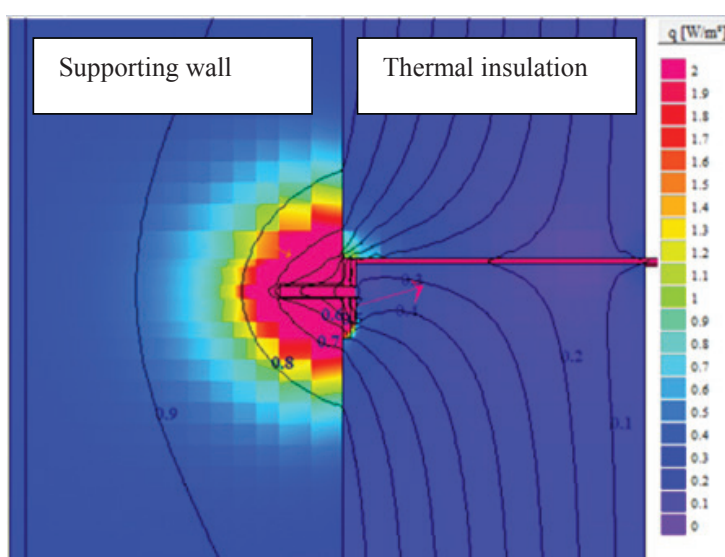

Table 1

Variations of calculated parameters

\section{Results}

Fig. 3

Behavior of the thermal flow through the pint thermal bridge 


\section{Fig. 4}

Thermal flow with

different thermal conductivity of the layer of the supporting wall:

a) $\lambda_{L}=0.1 \mathrm{~W} / \mathrm{m} \cdot \mathrm{K}$;

b) $\lambda_{L}=0.5 \mathrm{~W} / \mathrm{m} \cdot \mathrm{K}$;

c) $\lambda_{L}=1 \mathrm{~W} / \mathrm{m} \cdot \mathrm{K}$;

1 - supporting wall;

2 - thermal insulation

layer
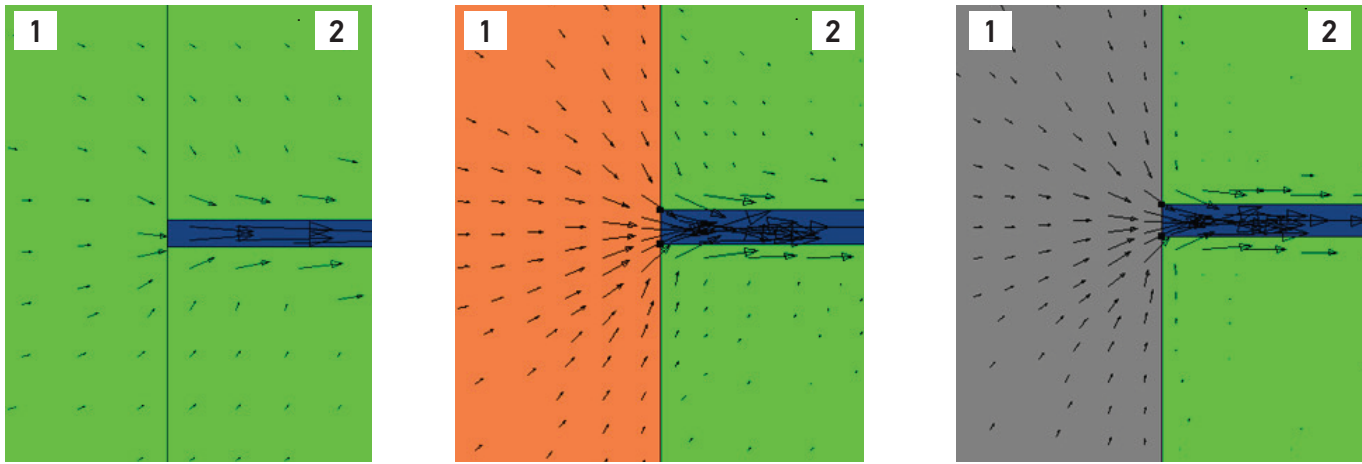

rials, which were located at the cold part of the insulation layer, and developed surfaces of the fixing elements are creating conditions for the dispersion of the thermal flow. Therefore, the value of the point thermal transmittance will be higher.

The obtained results show, that the fixing elements of the buildings with ventilated facade systems are going through the insulation layer and they have higher thermal conductivity compared with insulation layer. That's why there were high thermal flows in the intersection part and the effectiveness of thermal transmittance was increased. The point thermal transmittance ( $x$-value) depends on the type and material of the fixing element, as well as on the properties of the other construction materials: on the thermal conductivity and thickness of the insulation layer as well as on the thermal conductivity and thickness of the supporting wall.

\section{Evaluation of the dependency of thermal bridge}

Fig. 5 presents dependence of the point thermal transmittance ( $x$-value) of the fixing element from the thermal conductivity of the supporting wall ( $1^{\text {st }}$ var., Table 1$)$. If the thermal conductiv-

\section{Fig. 5}

Dependence of the calculated value of the thermal bridge of the fixing element on the value of the point thermal transmittance of the supporting wall

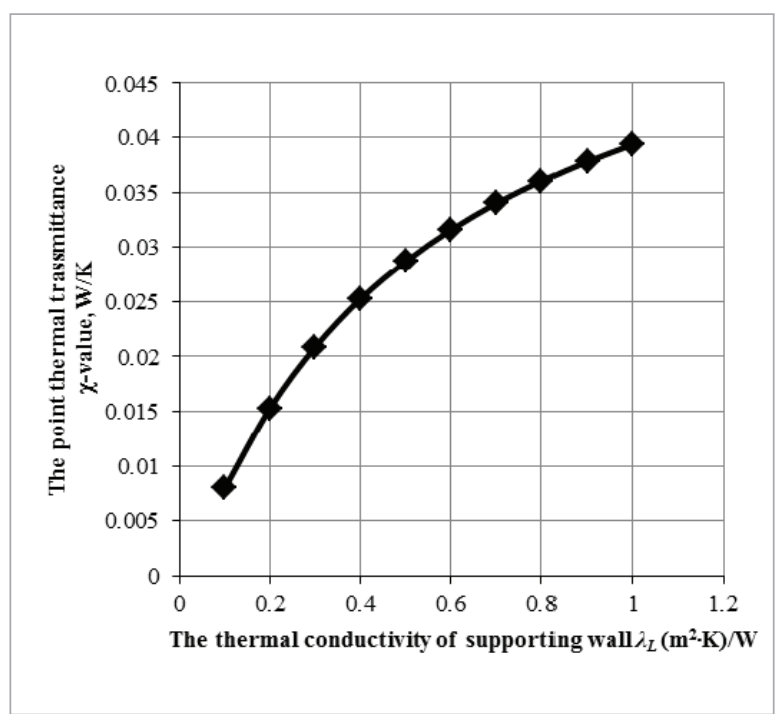

Logarithmic function of the point thermal transmittance ( $x$-value) of the supporting wall could be given as follow:

If Eq. 7 is transformed as: ity value $\lambda_{L}$ of the supporting wall is increased, the influence of the point thermal transmittance ( $\mathrm{x}$-value) to the total envelope's heat transmittance is increased by logarithmic distribution. Results, presented in Fig. 5 show, that when the thermal conductivity of the supporting wall $\lambda_{L}$ is increased from $0.1 \mathrm{~W} /(\mathrm{m} \cdot \mathrm{K})$ till $1 \mathrm{~W} /(\mathrm{m} \cdot \mathrm{K})$, value of the point thermal transmittance is increased from $x=0.008 \mathrm{~W} / \mathrm{K}$ till $\mathrm{x}=0.039 \mathrm{~W} / \mathrm{K}$ (it's almost 5 times higher), the supplement of the heat transmittance coefficient $\Delta \mathrm{U}$ is increased from 0.022 till $0.109 \mathrm{~W} /\left(\mathrm{m}^{2} \cdot \mathrm{K}\right)$, because of the influence of the fixing elements.

$$
\chi=\beta_{0}+\beta_{1} \ln \cdot \lambda_{L}
$$

$$
\ln \lambda_{T}=a
$$


We are getting expression of linear regression (9), which statistical reliability is checked later:

$\chi=\beta_{0}+\beta_{1} a$

Correlation between the value of the point thermal transmittance ( $x$-value) and the value of thermal conductivity coefficient of the supporting wall is strong $(R=0.997)$. The positive value of the correlation coefficient is showed, that with the increase of the thermal conductivity coefficient of the layer of the supporting wall $\left(\lambda_{L}\right)$ the point thermal transmittance ( $x$-value) was increased as well. It was not an accidental coincidence and correlation was statistically significant (the determined $p$-value $=$ $0<0.05)$.

With the use of linear regression method, determination coefficient was $R^{2}=0.994$. Relevance of the selected method was approved by ANOVA $(p$-value $=0)$. The tested multicolinearity problem (VIF $=1$ and it is less than 4) showed, that the problem was not present in the applicable model. Cook's maximum was 0 , so there were no extremes.

Fig. 6 is presenting P-P graphic, which shows results of the relative percentage frequency of the standardized residual errors and the normal random variable. Results presented in Fig. 7 show, that normality requirement were satisfied for the standardized residual errors. Therefore, in order to detect value of the point thermal transmittance ( $x$-value) according to the value of the thermal conductivity coefficient of the layer of the supporting wall, empirical equation could be used (Eq. 10):

$$
\chi=0.038+0.014 \cdot \ln \cdot \lambda_{L}
$$

transmittance, when the thickness of the construction was changed from 50 till $500 \mathrm{~mm}$ ( $2^{\text {st. }} \mathrm{var}$. Table 1). It was determined that when the thickness of the supporting wall was increased, the value of the point thermal transmittance was decreasing (from $x=0.034 \mathrm{~W} / \mathrm{K}$ till $\mathrm{x}=0.022 \mathrm{~W} / \mathrm{K}$ ). Respectively, the additive of the heat transmittance coefficient because of the influence of the fixing elements $(\Delta \mathrm{U}=\mathrm{x} \cdot \mathrm{n})$ decreased from 0.094 till $0.060 \mathrm{~W} /\left(\mathrm{m}^{2} \cdot \mathrm{K}\right)$.

Correlation between the value the point thermal transmittance ( $x$-value) and value of the thickness of the supporting wall $\left(d_{T}\right)$ was strong $(R=-0.988)$. A negative value of the

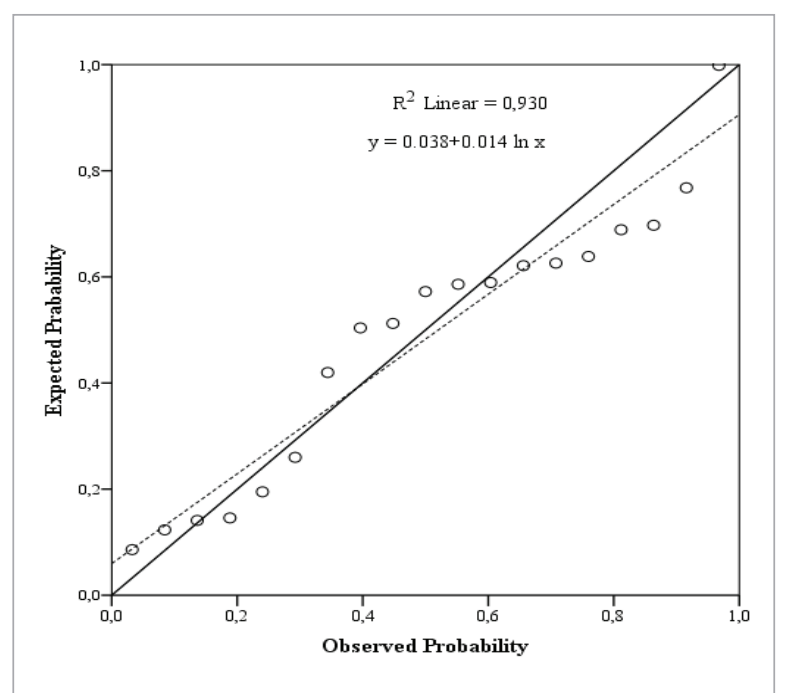

The thickness of the supporting wall $\left(d_{L}\right)$ also had influence on the value of the point thermal transmittance ( $2^{\text {nd }}$ var., Table 1$)$. Results presented in Fig. 7 , show the change of the value of the point thermal

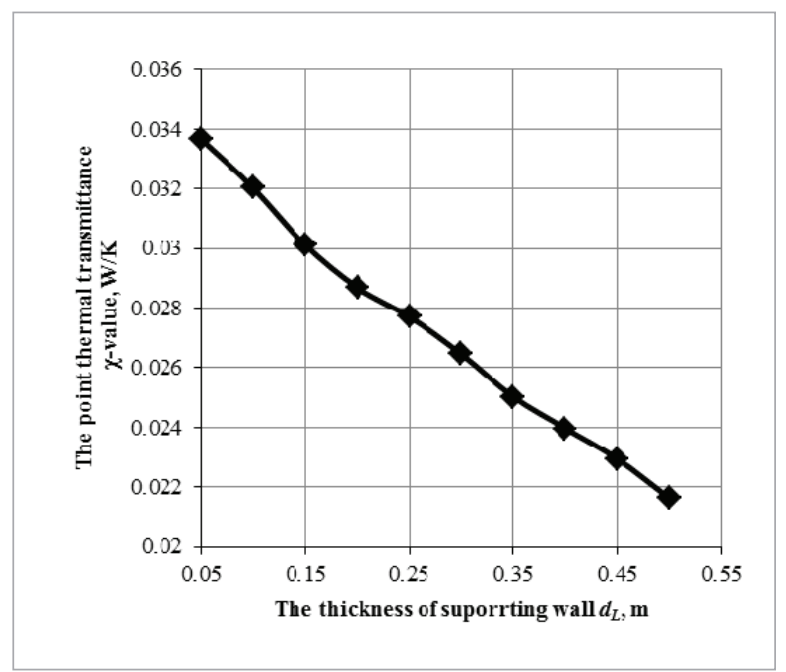

Fig. 6

Normal P-P plot of regression standardized residual, with different value of the point thermal transmittance of the supporting wall material

\section{Fig. 7}

The dependence of the calculated values of the point thermal transmittance on the thickness of the supporting wall 
Fig. 8

Normal P-P plot of regression standardized residual, with different value of supporting wall thickne

\section{Fig. 9}

The dependence of the calculated values of the point thermal transmittance on the values of thermal conductivity of the insulation layer

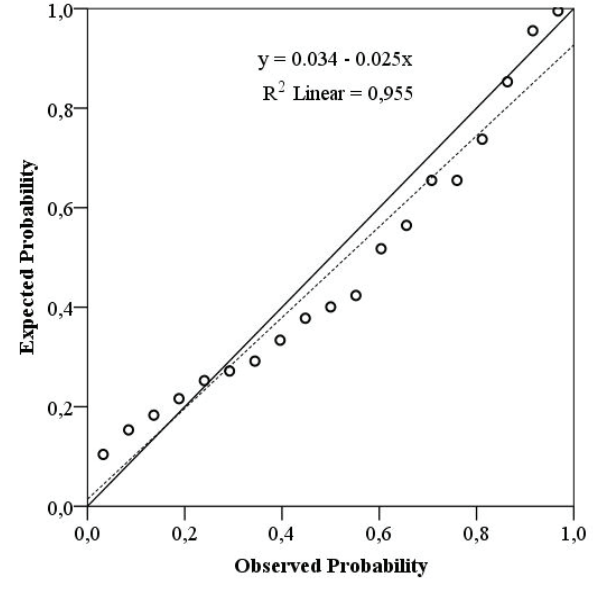

correlation coefficient $R$ indicated that with the increase of the value of thickness of the supporting wall, the value of the point thermal transmittance ( $x$-value) was decreasing. It was not an accidental coincidence and correlation was statistically significant (the determined $p$-value $=0<0.05$ ).

With the use of linear regression method, determination coefficient was $R^{2}=0.977$. Relevance of the selected method was approved by ANOVA ( $p$-value $=0)$. The tested multicolinearity problem (VIF $=1$ and it is less than 4) showed, that the problem was not present in the applicable model. Cook's maximum was 0 , so there were no extremes.

Results of P-P graphic presented in Fig. 8 show, that normality requirement were satisfied for the standardized residual errors. Therefore, in order to detect value of the point thermal transmittance ( $x$-value) according to the value of the thickness of the supporting wall $\left(d_{T}\right)$, empirical equation could be used (Eq. 11):

$$
\chi=0.034-0.025 d_{L}
$$

The values of the point thermal transmittance of the fixing elements also depend on the values of thermal conductivity of the insulation layer $\left(\lambda_{T}\right)$. Results presented in Fig. 9, show the change of the value of the point thermal transmittance, when the values of thermal conductivity of the insulation layer $\lambda_{T}$ was changed from $0.03 \mathrm{~W} /(\mathrm{m} \cdot \mathrm{K})$ till $0.04 \mathrm{~W} /(\mathrm{m} \cdot \mathrm{K})$ ( $3^{\text {st. }}$ var. Table 1$)$. It was determined, that when the thermal conductivity coefficient of the insulation layer $\left(\lambda_{T}\right)$ was increased, the value of the point thermal transmittance was decreasing from $0.029 \mathrm{~W} / \mathrm{K}$ till $0.028 \mathrm{~W} / \mathrm{K}$. Respectively, the additive of the heat transmittance coefficient because of the influence of the fixing elements $(\Delta U=x \cdot n)$ decreased from 0.081 till $0.078 \mathrm{~W} /(\mathrm{m} 2 \cdot \mathrm{K})$.

Correlation between the value of the point thermal transmittance and value of thermal conductivity coefficient of the insulation layer existed $(R=-0.999)$. A negative value of the correlation coefficient $R$ indicated that with the increase of the value of thermal conductivity coefficient of the insulation layer, the value of the point thermal transmittance was decreasing. It was not an accidental coincidence and correlation was statistically significant (the determined $p-$ value $=0<0.05$ )

With the use of linear regression method, determination coefficient was $R^{2}=0.999$. Relevance of the selected method was approved by ANOVA ( $p$-value $=0)$. The tested multicolinearity problem (VIF $=1$ and it is less than 4) showed, that the problem was not present in the applicable model.

Therefore, in order to detect value of the point thermal transmittance according to the value of thermal conductivity of the insulation layer, empirical equation could be used (Eq. 12): 


$$
\chi=0.032-0.093 \lambda_{T}
$$

Fig. 10 is presenting P-P graphic, which shows results of the relative percentage frequency of the standardized residual errors and the normal random variable. According to these results it can be stated, that normality requirement were satisfied for the standardized residual errors.

Results presented in Fig. 11, show the change of the value of the point thermal transmittance, when the thickness of the insulation layer $d_{T}$ was changed from $100 \mathrm{~mm}$ till $200 \mathrm{~mm}$ (4 var. of the calculation, Table 1). It was determined, that when the thickness of the insulation layer was increased till $150 \mathrm{~mm}$, the value of the point thermal transmittance was increasing. Later this tendency of increase is not so strong. When the thickness of the insulation layer was increased till $180 \mathrm{~mm}$, the value of the point thermal transmittance $x$ was reaching $0.02935 \mathrm{~W} / \mathrm{K}$. Respectively, the additive of the heat transmittance coefficient $\Delta U$ because of the influence of the fixing elements was increasing up to $0.082 \mathrm{~W} /$ $\left(\mathrm{m}^{2} \cdot \mathrm{K}\right)$. That showed, that the value of the point thermal transmittance dependence was not linear. Therefore, the curve presented in the Fig. 11 could be described by following dependence (13):

$$
\chi=\beta_{0}+\beta_{1} d_{T}^{2}
$$

By transforming (14) this dependence we are getting linear regression expression (15), which statistical significance is tested later.

$$
d_{T}^{2}=a
$$

$$
\chi=\beta_{0}+\beta_{1} \cdot a
$$

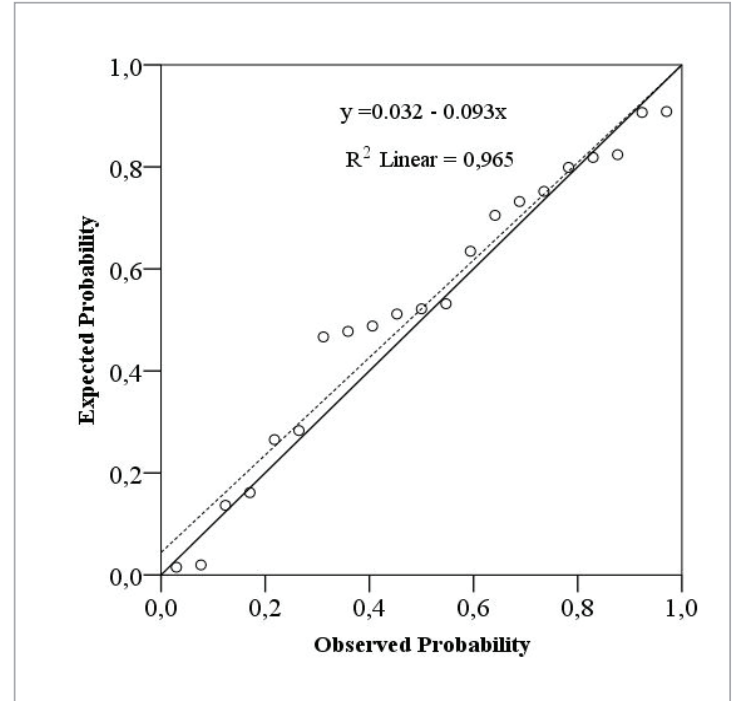

Fig. 10

Normal P-P plot of regression standardized residual, with different value of thermal conductivity of the insulation layer

Fig. 11

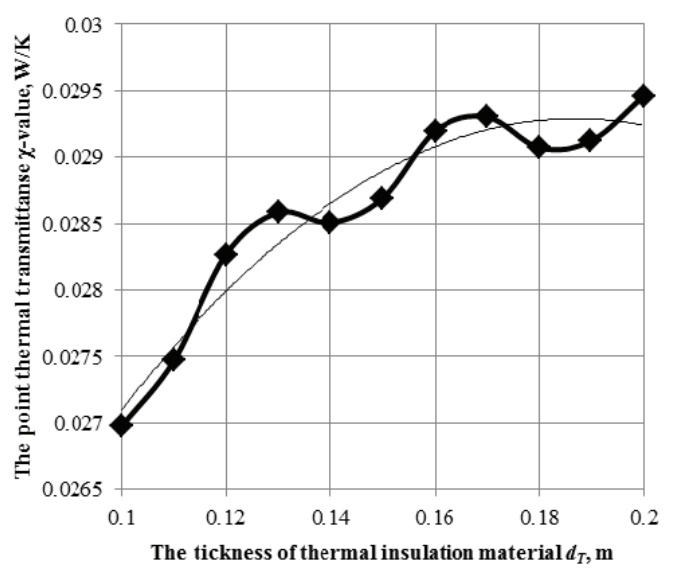

The dependence of the calculated values of the point thermal transmittance on the thickness of the insulation layer

Fig. 12

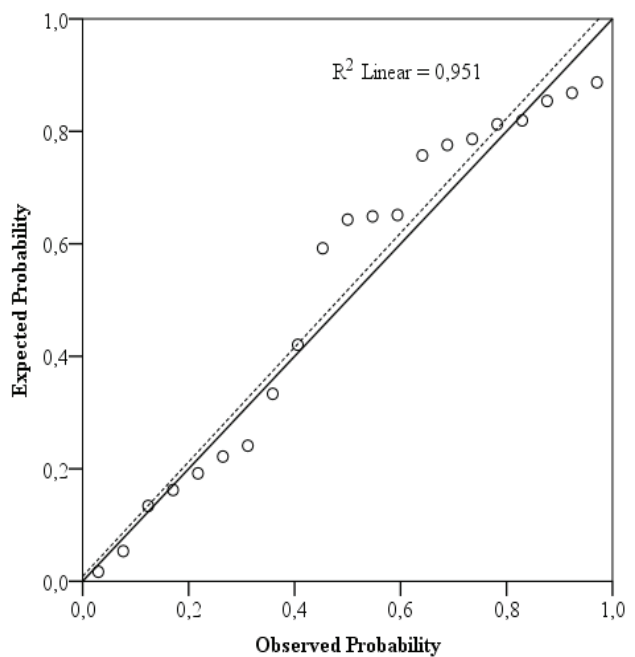

Normal P-P plot of regression standardized residual, with different value of thickness of the insulation layer 
With the use of linear regression method, determination coefficient was $R^{2}=0.766$. Relevance of the selected method was approved by ANOVA $(p$-value $=0)$. The tested multicolinearity problem (VIF $=1$ and it is less than 4) showed, that the problem was not present in the applicable model. Cook's maximum was 0.01 , so there were no extremes.

Fig. 12 is presenting P-P graphic, which shows results of the relative percentage frequency of the standardized residual errors and the normal random variable. According to these results it can be stated, that normality requirement were satisfied for the standardized residual errors. Therefore, in order to detect value of the point thermal transmittance according to the value of the thickness of the insulation layer, empirical equation could be used (Eq. 16):

$$
\chi=0.027+0.067 d_{T}^{2}
$$

The point thermal transmittance (value-x) calculation results are showing, that the point thermal transmittance ( $x$ - value) depends on the thickness and thermal properties of building envelop. According to the results (Fig. 13), it can be stated, that from all tested factors, the biggest influence to the value of the point thermal transmittance and to the increase of the heat transmittance coefficient of all construction could have thermal conductivity of the layer of the supporting wall (envelope's $U$ value may increase up to 35\%). This factor is very important in the practice. Material of the supporting wall can be different, from the masonry with good thermal properties to the monolithic concrete, which has poor thermal conductivity properties. In particular, it is important to properly evaluate houses, which are additionally insulated and construction of the wall may be not completely clear. It is also very important to select properly the material between the aluminum fixing element and construction material (interim, sheath), which can significantly reduce the flow of heat between the aluminum elements and dense, heat-conductive material of the supporting structure. When designing energy efficient buildings, where thermal insulation material thickness must be large in order to fulfill air tightness requirements set for these buildings, it is important to know that with the increase of the thickness of the thermal insulation layer, the influence of the point thermal transmittance (value-x) to the total heat transmittance coefficient is increasing up to certain limit.

Then the influence of the thermal properties of thermal insulation layer on the value of the point thermal transmittance is analyzed, it can be observed, that with the increase of the effectiveness of the thermal insulation layer, the value of the point thermal transmittance is increasing. This tendency is due to the high difference of the thermal conductivity coefficient values of thermal insulation material and aluminum fixing element. The higher thermal conductivity of the material, located on one or another part of the insulation layer, will increase the value of the point thermal transmittance because of the better conditions for the heat flow to collect (inner part) or spread (external part). However, the use of the effective insulation materials in envelop will reduce heat loss more significantly than increase because of the increased the point thermal transmittance (value-x). Therefore, the values of the point thermal transmittance might be higher if polymer material with "solid, nonelastic structures" are used in ventilated systems. An important fact is that, the aluminum elements are among the most conductive materials, so the use of fixing elements made from other materials (steel, fiberglass) material will significantly decrease their influence on envelop's thermal conductivity.

When the analyses of the average values of selected factors were made, it can be observed (Fig. 13), that all factors analyzed in this work are significant, so they should be assessed holistically. 
When the dependence of the point thermal bridges is made because of different parameters of the construction (thickness and thermal properties of the materials), it is possible to predict values of the point thermal transmittance if we know the value calculated for the basic design variant and differences of the construction from the basic one. It is important for the design of energy efficient performance buildings, because the calculation of the point thermal transmittance (value-x) is complicated, requiring additional knowledge, special software and the skills to use them. For these reasons, the point thermal bridges are quite often ignored in the practice. This might lead to large errors in assessing the energy efficiency of buildings and the design of heating and ventilation systems.

Studies have shown, that the value of the point thermal transmittance, which depended on the thermal properties of the envelop and thickness of the layers (to which aluminum fixing element is fifed), might increase to $35 \%$. The higher thickness of the supporting wall and coefficient of thermal conductivity of insulation layer, the lower the value of the point thermal transmittance. Meanwhile, the dependence of the point thermal transmittance on the thickness of insulation layer and thermal conductivity coefficient of the supporting wall was not linear.

When the dependence of the values of the point thermal transmittance from the facade system components (thermal properties and thickness of the supporting wall material; type and material of the fixing element; properties and dimensions of thermal insulation material) is determined, the values of the point thermal transmittance of the selected construction design might be find by simplified calculations according to existing dependencies formulas or graphics.

The dependence of the point thermal bridge established in this work, requires more detailed assessment of these bridges. It should not be limited to typical schemes, which often ignore the precise thickness and characteristics of the material.
Fig. 13

Increase of envelope's $U$ value because of the influence of different factors

Conclusions
Ascione F., Bianco N., De Masi, R.F., Mauro, G.M., Musto, M., Vanoli G.P. Experimental validation of a numerical code by thin film heat flux sensors for the resolution of thermal bridges in dynamic conditions. Applied Energy, 2014; 124:213-222. http://dx.doi.org/10.1016/j.apenergy.2014.03.014

Ascione F., Bianco N., de Rossi F., Turni G., Vanoli G.P. Different methods for the modeling of thermal bridges into energy simulation programs: comparisons of accuracy for flat heterogeneous roofs in Italian climates. Applied Energy, 2012; 97:405-418. http://dx.doi.org/10.1016/j. apenergy.2012.01.022
Berggren, B., Wall, M. Calculation of thermal bridges in (Nordic) building envelopes - Risk of performance failure due to inconsistent use of methodology, Energy and Building, 2013; 65:331-339. http://dx.doi.org/10.1016/j. enbuild.2013.06.021

Capozzoli, A., Gorrino, A., Corrado, V. A building thermal bridges sensitivity analysis. Applied Energy, 2013; 107:229-243. http://dx.doi. org/10.1016/j.apenergy.2013.02.045

Cappelletti, F., Gasparella, A., Romagnoti, P., Baggio, P. Analysis of the influence of installation 
thermal bridges on windows performance: the case of clay block walls, Energy and Buildings, 2011; 43:1435-1442. http://dx.doi.org/10.1016/j. enbuild.2011.02.004

Citterio, M., Cocco, M., Erhorn-Klutting, H. Thermal bridges in the EPBD context: overview on MS apptoaches in regulations, in: ASIEPI Information Paper. 2008.

De Andelis, E., Serra, E. Light steel-frame walls: thermal insulation performances and thermal bridges. Energy Procardia, 2014; 45:362-371. http:// dx.doi.org/10.1016/j.egypro.2014.01.039

EN ISO 14683:2008 Thermal bridges in building construction - Linear thermal transmittance Simplified methods and default values.

EN IOS 10211:2008 Thermal bridges in building construction - Heat flows and surface temperatures - Detailed calculations.

Evola, G., Margani, G., Marletta, L. Energy and cost evaluation of thermal bridge correction in Mediterranean climate, Energy and Buildings, 2011; 43:2385-2393. http://dx.doi.org/10.1016/j. enbuild.2011.05.028

European Commission. Directive 2010/31/EU of the European Parliament and of the Council of 19 th May 2010 on the energy performance of buildings, Available from internet:http://eur-lex.europa.eu/ legal-content/EN/ALL/?uri=CELEX:32010L0031.

Ge, H., McClung, V.R., Zhang, S. Impact of balcony thermal bridges on the overall thermal performance of multi-unit residential buildings: a case study, Energy and Buildings, 2013; 60:163-173. http:// dx.doi.org/10.1016/j.enbuild.2013.01.004

Gao, Y., Roux, J.J., Zhao, L.H., Jiang, Y. Dinamical building simulation: a low order model for thermal bridges losses, Energy and Buildings, 2008; 40:2236-2243. http://dx.doi.org/10.1016/j. enbuild.2008.07.003

Gomes, A.P., de Souza, H.A., Tribess, A. Impact of thermal bridging on the performance of building using Light Steel Framing in Brazil. Applied Thermal Engineering, 2013; 52:84-89. http://dx.doi. org/10.1016/j.applthermaleng.2012.11.015
Martin, K., Escudero, C., Erkoreka, A., Flores, I., Sala, J.M. Equivalent wall method for dynamic characterization of thermal bridges, Energy and Building, 2012; 55:704-714. http://dx.doi. org/10.1016/j.enbuild.2012.08.024

Martin, K., Erkoreka, A., Flores, I., Odriozola, M., Sala, J.M. Problems in the calculation of thermal bridges in dynamic conditions. Energy and Buildings, 2011; 43:529-535. http://dx.doi. org/10.1016/j.enbuild.2010.10.018

Petranek, V., Subrit, R., Plachy, J., Nevrivova, L., Petricek, T., Kalousek, L., Caha, Z. Thermal Bridgrs in Insulation System. Thermal, Power and Electrical engineering, pts. 1 and 2., 2013; 732-733:182-185.

STR 2.05.01:2013. Pastatu energinio naudingumo projektavimas [Energy performance of Buildings Design]. Vilnius, Ministry of Environment of Republic of Lithuania, 2005.

Tadeu, A., Simoes, I., Simoes, N., Prata, J. Simulation of dynamic liner thermal bridges using a boundary element method model in the frequency domain, Energy and Building, 2011; 43:3685-3695. http://dx.doi.org/10.1016/j. enbuild.2011.10.001

Theodosiou, T.,G., Papadopoulos, A., M. The impact of thermal bridges on the energy demand of buildings with double brick wall constructions. Energy and Buildings, 2008; 40:2083-2089. http:// dx.doi.org/10.1016/j.enbuild.2008.06.006

Theodosiou, T., Tsikaloudaki, K., Bikas, D., Aravantinos, D., Kontoleon, K.N. Assessing the use of simplilied and analytical methods for approaching thermal bridges with regard to their impact on the thermal performance of the building envelope. World SB 14 Conference on the Sustainable Building: Result, 2014, October 28-30 $0^{\text {th }}$, Barcelona, Span. Available from internet: http://wsb14barcelona.org/programme/pdf poster/P-059.pdf

Qasass, R., Gorgolewski, M., Ge, H. Timber framing factor in Toronto residential house construction. Architectural Science Review, 2014; 57(3):159-168. http://dx.doi.org/10.1080/000386 28.2013.869193 
JOLANTA

ŠADAUSKIENE்

Assoc. Professor

Kaunas University of Technology, Faculty of Civil Engineering and Architecture, Department of Building Energy

Systems

Main research area

Energy efficiency of buildings, heat transfer and thermal insulation, building envelope humidity behavior

\section{Address}

Studentu st. 48, LT44403, Kaunas, Lithuania Tel. +370 37350453

E-mail:

jolanta.sadauskiene@ ktu.lt

\section{JUOZAS \\ RAMANAUSKAS \\ Researcher \\ Laboratory of Building Physics at the Institute of Architecture and \\ Construction, KTU \\ Assoc. Professor \\ Kaunas University of Technology, Faculty of Civil Engineering and Architecture, Department of Building Materials}

\section{Main research area}

Energy efficiency of buildings, heat transfer and thermal insulation, building envelope humidity behaviour

\section{Address}

Tunelio st. 60, LT-44405, Kaunas, Lithuania Tel. +370 37350779 E-mail: juozas.ramanauskas@ ktu.lt

\section{LINA ŠEDUIKYTĖ \\ ANDRIUS BUSKA}

Assoc. Professor

Kaunas University of Technology, Faculty of Civil Engineering and Architecture, Department of Building Energy Systems

\section{Main research area}

Microclimate of buildings, live cycle of buildings, energy efficiency of buildings

\section{Address}

Studentu st. 48, LT44403, Kaunas, Lithuania Tel. +370 37350453

E-mail:

lina.seduikyte@ktu.lt
Dr. Technical Manager

Company „ROCKWOOL“

Main research area

Thermal properties of materials, heat transfer and thermal insulation

\section{Address}

A. Goštauto st. 40B, LT-01112 Vilnius,

Lithuania

Tel. +370 52126024

E-mail:

andrius.buska@

rockwool.com
About the authors 